\title{
VENTILATORY FUNCTION TESTS. I. VOLUNTARY VENTILATION CAPACITY
}

\author{
BY JOHN S. GRAY, DAVID R. BARNUM, HARL W. MATHESON, AND \\ SIDNEY N. SPIES \\ (From the Department of Physiology, Northwestern University Medical School, Chicago)
}

(Submitted for publication December 3, 1949; accepted, February 13, 1950)

An important element in any battery of tests designed to analyze the functional status of an organ is a quantitative measure of the capacity of that organ to carry on its specific function. In testing the functional status of the pulmonary bellows, therefore, a quantitative measure of its capacity to produce an alternating flow of air in and out of the lungs is desirable.

Several methods have been proposed for determining the ventilatory capacity of the lungs. Early attempts to utilize the vital capacity, which is essentially a static volume, as a test of ventilation capacity, which is a dynamic rate, met with little success $(1-4)$. Later attempts to utilize the maximum ventilatory response to $\mathrm{CO}_{2}$ inhalation (5-8) or to severe exercise $(1,3,7,8)$ have likewise proved unsatisfactory. Both are distressing and even dangerous to persons who are ill. Furthermore, both yield ambiguous results for they confound ventilation capacity and sensitivity to $\mathrm{CO}_{2}$ in the one case and ventilation capacity and cardiovascular capacity in the other. Finally, neither the $70 \mathrm{~L} . / \mathrm{min}$. maximum response to $\mathrm{CO}_{2}$ nor the $120 \mathrm{~L} . / \mathrm{min}$. maximum response to exhausting exercise approaches the capacity of the pulmonary bellows.

The most promising method of determining ventilation capacity depends upon voluntarily ventilating the lungs at the maximum rate. This procedure was first explored by Hermannsen (7) and further developed by Cournand, Richards and Darling (9). It has had a variety of names, the most common in German being "voluntary maximum ventilation" and in English "maximum breathing capacity." The latter term, however, has also been applied to the exercise procedure. In order to reduce confusion and ambiguity the following self-evidence terminology is recommended: voluntary ventilation capacity, exercise ventilation capacity, and $\mathrm{CO}_{2}$ ventilation capacity.

The purpose of the present study was to stand- ardize the procedure for measuring the voluntary ventilation capacity, to determine its reliability, and to establish normal values.

\section{METHODS}

The apparatus. The standard Benedict-Roth basal metabolism machine was employed. In order to reduce air-flow resistance in the machine, the valves were removed, thus permitting both tubes to conduct air in both directions. In order to avoid the unpleasant sensation and respiratory inhibition which accompany the acapnia ordinarily produced by voluntary over-ventilation, the soda-lime absorber for $\mathrm{CO}_{2}$ was also removed from the machine. The kymograph on this machine is too slow to record rapid breathing, and the labor involved in measuring minute-volume from a kymograph tracing is considerable. In order to avoid these difficulties a mechanical ventilometer was used to sum and record the successive inspiratory excursions of the spirometer. Several designs were used, which depended upon a fine ratchet and pawl for translating the alternating rotation of the pulley wheel of the spirometer into an unidirectional rotation of a recording wheel. The latter operated either a mechanical counter through a clutch mechanism, or an electrical counter through a micro-switch. In either case recording could be started and stopped at will during operation of the spirometer.

The procedure. The subject is instructed as to the nature of the test, and directed "to breathe as hard as he possibly can, the idea being to breathe the maximum volume of air in and out of the machine in 20 seconds." $\mathrm{He}$ is told that the machine is so constructed as to prevent dizziness from overbreathing, and a practice trial demonstrates this. No directions are given as to the pattern of rate or depth that should be used; his attention is focused on moving air. The complex muscular act of respiration is coordinated at subconscious levels; any attempt to impose a conscious pattern merely impairs performance. If during the practice trial the subject is seen to be concentrating on taking maximum individual breaths or cycling at the maximum rate, he is re-directed to keep the air flowing as fast as possible.

The spirometer bell is set to near its lowest position. The nose-clip is adjusted and the mouthpiece inserted, with the adjacent valve opened to outside air. The subject is then directed to take a deep breath and hold it, while the valve is turned in order to open the mouthpiece to the spirometer. At the signal "go" the subject 
TABLE I

Characteristics of samples of healthy persons studied

\begin{tabular}{|c|c|c|c|c|c|c|c|c|c|c|c|}
\hline \multirow{2}{*}{$\begin{array}{c}\text { Sample } \\
\text { No. }\end{array}$} & \multirow{2}{*}{$\begin{array}{c}\text { Subjects } \\
\text { Type }\end{array}$} & \multirow[b]{2}{*}{ Sex } & \multirow[b]{2}{*}{ No. } & \multicolumn{2}{|c|}{ Age, yrs. } & \multicolumn{2}{|c|}{ Height, in. } & \multicolumn{2}{|c|}{ Weight, lbs. } & \multicolumn{2}{|c|}{$\begin{array}{l}\text { Surf. area, } \\
\text { sq. } m .\end{array}$} \\
\hline & & & & Mean & St. D. & Mean & St. D. & Mean & St. D. & Mean & St. D. \\
\hline $\begin{array}{l}1 \\
2 \\
3 \\
4\end{array}$ & $\begin{array}{l}\text { Aviation cadets } \\
\text { Medical students } \\
\text { Medical students } \\
\text { Nurses }\end{array}$ & $\begin{array}{l}\mathrm{M} \\
\mathrm{M} \\
\mathbf{M} \\
\mathrm{F}\end{array}$ & $\begin{array}{r}89 \\
140 \\
54 \\
40\end{array}$ & $\begin{array}{l}20.85 \\
24.26 \\
23.83 \\
24.28\end{array}$ & $\begin{array}{l}2.54 \\
4.18 \\
3.12 \\
5.84\end{array}$ & $\begin{array}{l}69.66 \\
70.52 \\
70.06 \\
64.93\end{array}$ & $\begin{array}{l}2.57 \\
2.31 \\
2.29 \\
2.73\end{array}$ & $\begin{array}{l}160.6 \\
159.0 \\
163.5 \\
124.0\end{array}$ & $\begin{array}{l}14.5 \\
19.5 \\
18.8 \\
13.5\end{array}$ & $\begin{array}{l}1.88 \\
1.89 \\
1.90 \\
1.60\end{array}$ & $\begin{array}{l}0.11 \\
0.13 \\
0.075 \\
0.11\end{array}$ \\
\hline
\end{tabular}

begins to breathe as hard as possible. After a short running start, the ventilometer is engaged. After 20 seconds the ventilometer is disengaged, and the subject allowed to rest. The spirometer temperature and ventilometer readings are recorded.

It should be noted that the test is begun with the spirometer nearly empty and the subject's lungs nearly full. This guarantees that the subject's respiratory excursions will lie within the range of the spirometer. It also prevents acapnia, since the initial lung air containing $\mathrm{CO}_{2}$ is diluted during the subsequent re-breathing with only a small volume of spirometer air lacking $\mathrm{CO}_{2}$.

The calculations. The results of the test are expressed in liters per minute, BTPS. A correction factor was therefore calculated which incorporated a factor of three to convert the 20 second interval to one minute, a calibration factor for the ventilometer, and a temperaturepressure conversion factor. Since the spirometer is used without the soda-lime absorber, the temperaturepressure factors ordinarily used with the metabolimeter are not applicable. Furthermore, as in the case of all lung volume measures, and ventilation, the appropriate standard conditions are those in the lungs, namely, ambient barometric pressure, 37 degrees centigrade and saturated with water vapor, commonly abbreviated to BTPS. The formula for the appropriate conversion factor is :

$$
f=\frac{B-p_{2} \mathrm{O}}{B-47} \cdot \frac{310}{T}
$$

in which $\mathrm{B}$ is the ambient barometric pressure, $\mathrm{pH}_{2} \mathrm{O}$ is the water vapor tension at the absolute spirometer temperature T. Since daily fluctuations in barometric pressure have so little effect on the factor, the local mean barometric pressure was used. Thus a table was constructed giving for each spirometer temperature a combined factor incorporating all corrections.

Subjects. The subjects for these experiments were all healthy young individuals. Some were aviation cadets studied at the Army Air Forces School of Aviation Medicine in 1945 (10). The remaining subjects were local medical students, nurses, and technicians. Four different operators conducted the determinations on the various groups. The age and physical characteristics of the several samples are presented in Table I.

\section{RESULTS}

Standardization of the method. Satisfactory determination of the ventilation capacity requires a procedure in which resistance to breathing, unpleasant side effects, interference with the respiratory pattern, and fatigue and learning effects are minimal. The first three of these were minimized by the procedure of the test as described above. The effects of fatigue and learning were investigated by conducting prolonged and repeated tests, the results of which are presented in Table II.

The possible effects of fatigue were investigated in both male and female subjects by conducting a continuous trial of one minute's duration, during which readings were taken at 20 second intervals. Only a 4 to 5 per cent reduction in ventilation capacity occurred over the minute period (Table II). Accordingly, the test was standardized at 20 seconds, since this is long enough to give accurate readings, and short enough to avoid fatigue.

The possible effects of learning were investigated by conducting three consecutive trials within a ten minute period at the first session with the subject; in some subjects duplicate trials were repeated at a subsequent session approximately one week later. A 12 per cent improvement in performance occurred between the first and second trials, but only 4 per cent or less between the second and third trials (Table II). No change occurred in performance between the fourth and fifth trials, one week later, although the mean of these two trials exceeded by 4 to 5 per cent the mean of second and third trials of the preceding week. These results revealed that most of the learning is completed after a single trial; accordingly the procedure has been standardized to include one practice trial, the results of which are discarded. 
TABLE II

Effect of fatigue and learning on voluntary ventilation capacity

\begin{tabular}{|c|c|c|c|c|c|c|c|c|}
\hline \multirow{2}{*}{ Description } & \multicolumn{2}{|c|}{ Subjects } & \multicolumn{3}{|c|}{ Initial trials } & \multicolumn{2}{|c|}{ Week later } & \multirow{2}{*}{$\begin{array}{l}\text { Per cent } \\
\text { change }\end{array}$} \\
\hline & No. & Sex & No. 1 & No. 2 & No. 3 & No. 4 & No. 5 & \\
\hline Continuous trials & $\begin{array}{l}25 \\
48\end{array}$ & $\stackrel{\mathbf{M}}{\mathbf{F}}$ & $\begin{array}{l}1441 \\
110.5\end{array}$ & $\begin{array}{l}142.1 \\
106.6\end{array}$ & $\begin{array}{l}137.5 \\
105.1\end{array}$ & & & $\begin{array}{l}-4.6 \\
-4.9\end{array}$ \\
\hline \multirow[t]{4}{*}{ Consecutive trials } & \multirow[t]{4}{*}{$\begin{array}{l}143 \\
283 \\
140\end{array}$} & \multirow{4}{*}{$\begin{array}{l}\mathbf{M} \\
\mathbf{M} \\
\mathbf{M} \\
\mathbf{F}\end{array}$} & \multirow{4}{*}{$\begin{array}{c}145.9 \\
\text { discarded } \\
\text { discarded } \\
\text { discarded } \\
\text { discarded }\end{array}$} & $\begin{array}{l}163.7 \\
161.0 \\
158.3\end{array}$ & $\begin{array}{l}169.2 \\
166.1 \\
163.0\end{array}$ & 167.2 & 167.7 & \multirow{4}{*}{$\begin{array}{l}+16 \\
+3.2 \\
+0.3^{*} \\
+4.3 \\
-1.0^{*} \\
+5.7\end{array}$} \\
\hline & & & & \multicolumn{2}{|c|}{160.6} & \multicolumn{2}{|c|}{167.5} & \\
\hline & & & & 108.6 & 110.1 & 116.1 & 114.9 & \\
\hline & & & & \multicolumn{2}{|c|}{109.6} & \multicolumn{2}{|c|}{115.8} & \\
\hline
\end{tabular}

* Between Trials No. 4 and No. 5 only.

Reliability of the method. The reliability of the measurement of voluntary ventilation capacity was determined by calculating the correlation coefficient for repeated measurements, in both male and female subjects (Table III). For duplicate determinations conducted on the same day, the reliability coefficients ranged from 0.79 to 0.93 , the values being consistently higher in females; for the means of duplicate determinations conducted a week apart, the coefficients were practically identical. Reliability might be expected to be greater on tests conducted at a single sitting than on tests a week apart, since under the latter condition the feature being measured has more opportunity to undergo change. However, reliability should be higher for tests based on the mean of several trials, than for single determinations. These contrasting influences apparently cancelled out in the present.instance, leaving the coefficient unaltered.

It is common procedure in capacity determination to take the "best" rather than the mean of several trials, on the principle that the "true" capacity cannot be less than what has actually been performed. However, this practice neglects the

TABLE III

Reliability of measurement of voluntary ventilation capacity

\begin{tabular}{|c|c|c|c|c|}
\hline \multirow{2}{*}{ Trials analyzed } & \multicolumn{2}{|c|}{ Males } & \multicolumn{2}{|c|}{ Females } \\
\hline & No. & $\mathbf{r}$ & No. & $\mathbf{r}$ \\
\hline $\begin{array}{l}\text { Two trials, initial day (No. } 2 \text { vs. No. } 3 \text { ) } \\
\text { Two trials, a week later (No. } 4 \text { vs. No. 5) } \\
\text { Means of paired trials, a week apart (Nos. 2- } \\
3 \text { os. Nos. 4-5) } \\
\text { Best of paired trials, a week apart }\end{array}$ & \begin{tabular}{l|}
283 \\
140 \\
140 \\
140
\end{tabular} & $\begin{array}{l}0.790 \\
0.797 \\
0.742 \\
0.744\end{array}$ & $\begin{array}{l}40 \\
40 \\
40 \\
40\end{array}$ & $\begin{array}{l}0.867 \\
0.930 \\
0.934 \\
0.948\end{array}$ \\
\hline
\end{tabular}

important fact that extreme values are least representative of the thing measured. In the present experiments, no improvement in reliability was obtained by using the "best" of duplicate trials rather than their mean. On the basis of these findings, the practice of basing the voluntary ventilation capacity on the mean of duplicate trials has been established.

A reliability coefficient of 0.8 indicates that the variation in ventilation capacity between different individuals is considerably greater than the variation encountered within a single individual when the test is repeated. The procedure, therefore, has appreciable power to distinguish between different normal individuals. In pulmonary disease, however, the ventilation capacity may be reduced to less than 10 per cent of normal. The power of the test to detect such abnormalities is of course much greater than its power to differentiate between normal persons.

Normal values. Normal values for voluntary ventilation capacity for the several groups studied are presented in Table IV. In accordance with

TABLE IV

Normal values for voluntary ventilation capacity and correlations

\begin{tabular}{|c|c|c|c|c|c|c|c|}
\hline \multicolumn{3}{|c|}{ Subjects } & \multicolumn{3}{|c|}{$\begin{array}{c}\text { Normal values, } \\
\text { BT PS }\end{array}$} & \multicolumn{2}{|c|}{ Correlation } \\
\hline Type & Sex & No. & Mean & St. & $\begin{array}{l}\text { Coef. } \\
\text { var. }\end{array}$ & $\begin{array}{l}\text { With } \\
\text { age }\end{array}$ & $\begin{array}{l}\text { With } \\
\text { surf. } \\
\text { area }\end{array}$ \\
\hline $\begin{array}{l}\text { Aviation cadets } \\
\text { Medical students } \\
\text { Both combined } \\
\text { Nurses }\end{array}$ & $\begin{array}{l}\mathbf{M} \\
\mathbf{M} \\
\mathbf{M} \\
\mathbf{F}\end{array}$ & $\begin{array}{r}89 \\
194 \\
283 \\
40\end{array}$ & $\begin{array}{l}167.8 \\
166.8 \\
167.1 \\
115.8\end{array}$ & $\begin{array}{l}22.1 \\
20.5 \\
21.0 \\
20.9\end{array}$ & \begin{tabular}{l|}
13.1 \\
12.3 \\
12.6 \\
18.0
\end{tabular} & $\begin{array}{r}+0.094 \\
+0.042\end{array}$ & $\begin{array}{l}+0.307 \\
+0.301\end{array}$ \\
\hline
\end{tabular}


TABLE V

Normal values for ventilation capacity

\begin{tabular}{|c|c|c|c|c|c|c|c|c|}
\hline \multirow{2}{*}{ Author } & \multicolumn{2}{|c|}{ Subjects } & \multicolumn{3}{|c|}{ Vol. vent. cap. } & \multicolumn{3}{|c|}{ Method } \\
\hline & No. & Sex & Mean & St. dev. & Coef. var. & Corr. & Acapnia & Duration \\
\hline $\begin{array}{l}\text { Hermannsen (7) } \\
\text { Malamos (11) } \\
\text { Zorn (12) } \\
\text { Cournand (9) } \\
\text { Cournand (9) } \\
\text { Battro and Labourt (13) } \\
\text { Dripps and Comroe (8) } \\
\text { Present study } \\
\text { Present study }\end{array}$ & $\begin{array}{r}23 \\
68 \\
40 \\
20 \\
20 \\
10 \\
19 \\
283 \\
40\end{array}$ & $\begin{array}{l}\text { Both } \\
\text { M } \\
M \\
M \\
F \\
? \\
M \\
M \\
F\end{array}$ & $\begin{array}{r}99 \\
145 \\
128 \\
154 \\
100 \\
111 \\
166 \\
167 \\
116\end{array}$ & $\begin{array}{l}24.8 \\
34.6 \\
25.7 \\
30.9 \\
16.8 \\
35.3 \\
20.3 \\
21.0 \\
20.9\end{array}$ & $\begin{array}{l}25 \\
24 \\
20 \\
20 \\
17 \\
32 \\
12 \\
13 \\
18\end{array}$ & $\begin{array}{c}? \\
? \\
? \\
\text { BTPS } \\
\text { BTPS } \\
? \\
\text { ? } \\
\text { BTPS } \\
\text { BTPS }\end{array}$ & $\begin{array}{l}\text { Present } \\
\text { Present } \\
\text { ? } \\
\text { Present } \\
\text { Present } \\
\text { Present } \\
\text { Present } \\
\text { Avoided } \\
\text { Avoided }\end{array}$ & $\begin{array}{c}60 \mathrm{sec} . \\
10 \mathrm{sec} . \\
? \\
15-30 \\
15-30 \\
60 \mathrm{sec} . \\
30 \mathrm{sec} . \\
20 \mathrm{sec} . \\
20 \mathrm{sec} .\end{array}$ \\
\hline
\end{tabular}

the standardized procedure, the tests were all of 20 seconds' duration, and based upon the mean of duplicate trials, after at least one practice trial; if there was only one session with the subject, trials 2 and 3 were averaged, whereas, if there were two sessions, trials 4 and 5 were averaged.

The average ventilation capacity for 283 healthy young men was found to be $167.1 \mathrm{~L} . / \mathrm{min}$. and for 40 healthy young women, $115.8 \mathrm{~L} . / \mathrm{min}$., a significant sex difference. It should also be noted that identical values were obtained for the 89 aviation cadets (carefully selected from the standpoint of physical health, and highly motivated) and the 194 medical students.

The range of normal values was found to be the same for men and women as revealed by the standard deviation of approximately $\pm 21 \mathrm{~L}$. $/ \mathrm{min}$. Expressed as a percentage of the mean (coefficient of variation) this becomes \pm 13 per cent for men and \pm 18 per cent for women. On the basis of the usual decision that the "normal" range should include 95 per cent ( \pm 2 standard deviations) of the healthy population, these ranges become 125 to $209 \mathrm{~L}$./min. for men and 95 to $137 \mathrm{~L} . / \mathrm{min}$. for women.

The ventilation capacity was found to have no relationship to the age of the subject, within the comparatively narrow range studied (18 to 35 years) as shown by the non-significant correlation coefficients in Table IV. Obviously children and the aged would be expected to yield lower values. No correlation was found with height or weight alone, but in the case of surface area a significant correlation of very low magnitude was found. This correlation is so low, and the evidence of a direct proportionality is so poor, that voluntary ventilation capacity should not be expressed on a per unit surface area basis. In fact, the variability of this ratio is actually greater than that of the ventilation capacity alone. ${ }^{1}$

\section{DISCUSSION}

Previously reported normal values for voluntary ventilation capacity have been collected and are summarized in Table V. It can be seen that average normal ranging from 99 to $166 \mathrm{~L} . / \mathrm{min}$. have been reported for men, and that coefficients of variation have ranged from 12 to 32 per cent. The present value of $167 \pm 13$ per cent represents the highest mean, and nearly the lowest range of variation. Both of these differences are undoubtedly due to improved standardization of the procedure.

Aside from the variability of results, the lack of previous standardization of the method is also revealed in the table. Some investigators have failed to take the marked sex difference into account; none appear to have allowed for the learning factor. Very few have properly corrected their values to BTPS; ordinary room conditions give values in the neighborhood of 8 per cent too low and a mistaken correction to STPD yields values nearly 25 per cent too low. Many workers have imposed a respiratory pattern on the subject, which materially impairs performance on the test. None appear to have taken precautions to prevent the development of acapnia with its accompanying distress and involuntary inhibition of

1 Through error, the correlation between ventilation capacity and surface area was previously reported (10) to be 0.72 ; it was actually only 0.23 . 
respiration. This probably makes little difference in the short duration tests, but undoubtedly seriously affects the longer tests.

In view of this wide diversity of procedure, and the failure of many workers even to report normal values for their method, it is difficult to interpret quantitatively many of the results that have been reported in disease. Quantitatively, however, it is clear that the voluntary ventilation capacity is reduced in many respiratory diseases, and grossly so in asthma and emphysema.

It should be pointed out that the present values are based upon the healthy young adult population, and are not necessarily those to be expected of children, the aged, the infirm or those in poor health or of radically different body size. The present purpose is to provide adequate information regarding the ventilation capacity of a clearly defined healthy adult population to serve as a basis for the accurate detection and intelligent interpretation of deviations therefrom, regardless of the finally determined causes of such deviations.

\section{SUM MARY AND CONCLUSIONS}

1. A standardized procedure for the determination of voluntary ventilation capacity in man is described.

2. The procedure yielded normal values of 167 $\pm 21 \mathrm{~L} . / \mathrm{min}$. for 283 healthy young men and $116 \pm 21 \mathrm{~L} . / \mathrm{min}$. for 40 healthy young women, with reliability coefficients of 0.8 to 0.9 . These means are higher and the variabilities lower than previously reported because of improved standardization.

3. No useful degree of correlation between voluntary ventilation capacity and age, height, weight, or surface area could be established in the young adult population studied.

\section{BIBLIOGRAPHY}

1. Sturgis, C. C., Peabody, F. W., Hall, F. C., and Fremont-Smith, F., Clinical studies on respiration: relation of dyspnea to the maximum minute-volume of pulmonary ventilation. Arch. Int. Med., 1922, 29, 236.

2. Peabody, F. W., and Wentworth, J. A., Clinical studies on respiration: The vital capacity of the lungs and its relation to dyspnea. Arch. Int. Med., 1917, 20, 443.

3. Kaltreider, N. L., and McCann, W. S., Respiratory response during exercise in pulmonary fibrosis and emphysema. J. Clin. Invest., 1937, 16, 23.

4. Ornstein, G. G., and Epstein, I. G., Spirometry as procedure of determining pulmonary efficiency in pulmonary and heart disease. J. M. Soc. New Jersey, 1940, 37, 401.

5. Peabody, F. W., Clinical studies on respiration: a mechanical factor in the production of dyspnea in patients with cardiac disease. Arch. Int. Med., 1917, 20, 433.

6. Scott, R. W., Observation on pathologic physiology of chronic pulmonary emphysema. Arch. Int. Med., 1920, 26, 544.

7. Hermannsen, J., Untersuchungen uber die maximale Ventilationsgrosse (Atemgrenzwert). Ztschr. f. d. ges. exper. Med., 1933, 90, 130.

8. Dripps, R. D., and Comroe, J. H., Respiratory and circulatory response of normal man to inhalation of 7.6 and 10.4 per cent $\mathrm{CO}_{2}$ with comparison of maximal ventilation produced by severe muscular exercise, inhalation of $\mathrm{CO}_{2}$ and maximal voluntary hyperventilation. Am. J. Physiol., 1947, 149, 43.

9. Cournand, A., Richards, D. W., Jr., and Darling, R. C., Graphic tracings of respiration in study of pulmonary disease. Am. Rev. Tuberc., 1939, 40, 487.

10. Gray, J. S., and Green, E. L., Voluntary ventilation capacity: normal values and reliability of measurement. AAF School of Aviation Medicine Research report No. 449, 4 Dec. 1945. Also Federation Proc., 1946, 5, 35.

11. Malamos, B., Beitrag zur Lungenfunktionsprufung in der Klinik. Beitr. z. Klin. d. Tuberk., 1938, 92, 225.

12. Zorn, O., Die quantitative Lungen- und Kreislauffunktionsprufung bei Bergarbeitern. Beitr. z. Klin. d. Tuberk., 1940, 94, 544.

13. Battro, A., and Labourt, F. E., Consideraciones sobre la determinacion de la ventilacion maxima, la reserva pulmonar y la hiperpnea de los cardiacos. Rev. argent. de cardiol., 1943, 10, 83. 